\title{
DISCURSO DE RECEPÇÃO DO TÍTULO DE PROFESSOR EMÉRITO
}

SPEECH OF INVESTITURE AS AN EMERITUS PROFESSOR

Dalmo de Abreu Dallari

\author{
Agradecimentos: Congregação \\ Propositores \\ Saudação Gilberto Bercovici \\ Associação dos Antigos Alunos \\ C.A.XI de Agosto \\ Presentes
}

"Você ainda vai acabar professor da Faculdade do Largo São Francisco". Essa profecia foi a reação entusiasmada de um tio materno, Aurélio Leme Abreu, que trinta anos atrás havia saído da roça, do Sítio Três Barras, em Serra Negra, para a aventura de tentar ir além do curso primário e chegar a fazer um curso de medicina no Rio de Janeiro. Bem sucedido, apesar dos imensos obstáculos, e exercendo a Medicina em São Paulo, tio Aurélio, que bem sabia de minha origem modesta na mesma Serra Negra de sua infância, fez aquela profecia quando the entreguei o primeiro número do jornal acadêmico "XI de Agôsto" feito sob minha direção, com um texto de apresentação assinado por mim. Isso foi em 1953. Dez anos depois, em 1963, sem nunca ter deixado de ser aluno formal da escola, por ter feito sucessivos cursos de Especialização, anteriores à criação do Mestrado e Doutorado, fui aprovado em concurso para a Livre-Docência, tornando-me, então, professor das Arcadas. A profecia se cumpriu e já no início de 1964 fui indicado para reger uma turma do curso noturno, o que fiz com orgulho e o entusiasmo do antigo aluno, que nunca deixei de ser.

Cumprida minha trajetória de Professor, com intensa e contínua participação nas atividades administrativas e culturais da Faculdade, entremeadas por um mandato de Diretor, fui compulsoriamente aposentado, na forma de disposição constitucional, em 31 de Dezembro de 2001, continuando, entretanto, ligado às minhas queridas Arcadas pela condição de antigo aluno, da qual jamais me aposentarei.

Para minha surpresa e grande alegria, acolhendo generosa proposta de três mestres muito atuantes na vida da Escola, Fábio Comparato, amigo desde os bancos acadêmicos, companheiro e mestre nas lutas pelos Direitos Humanos, Gilberto Bercovici e Sebastião Tojal, dois expoentes das novas gerações de Professores, a douta Congregação da Faculdade concedeu-me o título, sumamente honroso, de Professor Emérito. A outorga desse título tem valor inestimável, pois me introduz na galeria de figuras exponenciais do Direito que enriqueceram a história desta Casa e que deram contribuição significativa para que ela se mantivesse na primeira linha das instituições de ensino jurídico no Brasil. 
Evidentemente, uma honraria desse porte, provinda de minha "alma mater" espiritual e intelectual, não se pede nem se recusa, mas provoca uma busca retrospectiva, numa espécie de auto-avaliação, rememorando a trajetória percorrida e buscando a identificação do que nela pode ter o valor de contribuição para o enriquecimento do prestígio das velhas Arcadas.

Analisando minha trajetória de Professor, vêm-me à lembrança algumas inovações que introduzi nas rotinas da docência da época e que provocaram, ao mesmo tempo, reações de entusiasmo e de indignação. Sendo um leitor apaixonado pelas aventuras do pensamento e influenciado por notáveis mestres que tive no Colégio Estadual Presidente Roosevelt, especialmente nos campos da Filosofia, da História, do Latim e do Grego, eu tinha conhecimento das comunidades de estudos que foram marcantes na Grécia antiga e se encontram na origem das Universidades modernas, ambientes de reflexão e discussão que faziam de mestres e alunos uma unidade de convivência intelectual e espiritual. E espontaneamente, com entusiasmo autêntico, procurei maior aproximação com os alunos, induzindo-os a um papel mais ativo no processo de aprendizagem. Assim, como complemento das aulas e para estimular a leitura e as discussões, passei a indicar obras consagradas ou capítulos de obras, de autores como Aristóteles, Maquiavel e Rousseau, para discussões semanais. Querendo que houvesse maior dinamismo e mais estímulo à polêmica, passei a indicar um relator e um revisor para cada texto, certo de que sempre haveria algumas divergências, o que seria muito bom para que os alunos sentissem uma espécie de desafio na defesa de seus pontos de vista e assim não houvesse o risco de exposições monótonas e enfadonhas. Com os alunos o resultado dessa inovação, que logo evoluiu para a implantação de seminários, foi o melhor possível. Mas alguns professores que tiveram conhecimento dessa iniciativa reagiram indignados, por considerarem que aproximar-se demais dos alunos e dar a eles um papel ativo no processo de aprendizagem era igualar-se aos alunos, o que degradava o Professor.

Isso tudo ocorria logo depois do golpe militar de $1^{\circ}$ de abril de 1964 , que teve a participação e o apoio de vários catedráticos desta Escola. É importante relembrar esse dado porque também em relação a isso minha atitude provocou fortes reações. Os lideres do golpe deram-lhe o rótulo de revolução redentora, mas analisando com os alunos os fatos e seus desdobramentos na área jurídica - e que me pareceu indispensável que eu fizesse, como Professor de Teoria do Estado - eu mostrava aos alunos que tinha ocorrido no Brasil um movimento político-militar que se enquadrava nos modelos que os teóricos registravam como golpes de Estado e não como revolução. A par disso, eu explicava aos alunos, também com base na teoria, que o novo sistema de governo implantado no Brasil, contrariando frontalmente a Constituição, era uma ditadura.

A conjugação desses dois fatores, o novo método de ensino e a classificação teórica do movimento político-militar, sobre a qual passei a ser convidado para falar em outras 
Faculdades e para grupos de resistência democrática, teve conseqüências muito positivas perante os alunos e, sem temer estar exagerado, posso dizer que teve também repercussão positiva para o prestígio da Faculdade. Apesar disso, e pelas circunstâncias do momento, foi a base de uma decisão da Congregação, cassando minha indicação para reger cursos e ministrar aulas, sob o fundamento de que estava anarquizando a Escola, comportando-se como se fosse mais um aluno e não um professor e, além disso, estimulando a rebeldia e pregando subversão. A interdição durou pouco, pois, tendo recorrido formalmente daquela decisão, na defesa do que eu sustentei ser meu direito de ministrar cursos, uma vez que tinha sido aprovado em concurso para Livre-Docência, pouco mais de um mês depois fui restaurado como Professor, com a única restrição de que eu só poderia lecionar no curso noturno, provavelmente por ser freqüentado por estudantes de origem mais modesta e não pelos futuros dirigentes do País. Mais tarde fui reconhecido e aceito pela maioria dos colegas de docência como inovador positivo, portador de ousadias que contribuíam para o aperfeiçoamento e a modernização dos métodos de ensino e para manter elevado o prestígio das nossas velhas e queridas Arcadas franciscanas.

Outro ponto que me parece ter contribuído para a avaliação positiva de meu desempenho como Professor da velha e sempre nova Academia, foi uma inovação na abordagem teórica dos temas da Teoria Geral do Estado. Inspirado por minhas convicções humanistas, mas também baseado em meus estudos de História, Sociologia, Antropologia e Teoria Política, procurei desde o início fazer a ligação das proposições teóricas abstratas com o mundo da realidade concreta. Para isso contribuíram muito as lições de notáveis mestres que tive no Largo de São Francisco, parecendo-me justo lembrar, neste momento, a influência do grande mestre Goffredo da Silva Telles Júnior, professor do primeiro ano, do início do curso jurídico, de quem ouvi que o Direito é a disciplina legítima da convivência comunitária e que seu fundamento básico é o amor ao próximo, que inspira o respeito para pessoa humana. Outro mestre eminente, cuja influência quero ressaltar agora, foi Miguel Reale, professor de Filosofia do Direito no último ano do curso, que, por sua teoria da tridimensionalidade jurídica, acentou a indispensável consideração do valor, como integrante necessário da norma jurídica, repondo a ética no mundo do Direito. Sob essas e outras influências, sem ignorar qualquer dos grandes teóricos e nenhuma das principais correntes de pensamento sobre o Estado, procurei, em primeiro lugar, fazer a abordagem crítica das proposições teóricas, indo muito além da mera exposição, fazendo também um esforço para traduzir em termos mais acessíveis as construções teóricas complexas e de compreensão às vezes difícil. A par disso, procurei sempre fazer o confronto das teorias com os acontecimentos concretos, através da história. Essa forma de abordagem foi registrada em meu livro "Elementos da Teoria Geral do Estado", de caráter didático, e a comprovação da boa receptividade desse tratamento dos temas, em princípio complexos, está no fato de que esse livro acaba de ser publicado em sua $27^{\mathrm{a}}$ edição. Creio 
que isso demonstra o acolhimento do método por eminentes mestres de Teoria do Estado e disciplinas afins, de muitas partes do Brasil, contribuindo para que eu seja bem avaliado como professor.

Finalmente, parece-me que também contribuíram para que eu fosse um professor bem-sucedido, e para que eu conquistasse o respeito de colegas de docência e alunos, dois fatos que considero relevantes. Um deles foi a manutenção da coerência entre os ensinamentos teóricos e a prática. Relembro aqui a observação aguda do Padre Antônio Vieira, no Sermão da Sexagésima, falando do ambiente de corrupção que havia no clero do Maranhão e dos efeitos que isso produzia. Pergunta o notável jesuíta: "Por que esses pregadores não conseguem frutos, por que sua pregação não obtém resultados?" E a resposta é fulminante: “É porque pregam apenas para ouvidos, não para olhos". Com isso queria dizer que contrariavam na prática o que diziam nos púlpitos, ficando evidente sua falta de autenticidade e fazendo com que ninguém levasse a sério seus ensinamentos. Outro fator que parece ter também contribuído para minha boa imagem de Professor foi a dedicação integral e constante à Faculdade do Largo de São Francisco. Desde o início de minha carreira docente, procurei conciliar todas as demais atividades com a efetiva integração nas atividades docentes e administrativas da Faculdade. Quando a douta Congregação me incluiu na lista tríplice para a escolha do Diretor e tive a honra de ser o escolhido pelo Reitor José Goldemberg, passei para o regime de dedicalção integral e fechei as portas de meu escritório de Advocacia, para que a dedicação à Escola fosse, de fato integral. E desde então nunca mais mudei de regime de trabalho e sempre fiz do exercício da docência uma espécie de Advocacia para todo o povo, fazendo também da Advocacia uma espécie de docência permanente para todo o povo, estimulando a crença no Direito e mostrando os caminhos jurídicos para a busca de efetividade na proteção e fruição dos direitos consagrados na Constituição e nas leis.

Por tudo isso, recebo com humildade, mas com alegria imensa, a enorma honraria que acaba de me ser concedida. Essa outorga generosa, feita por colegas que me acompanharam de perto e que bem conhecem meu desempenho como Professo, transmiteme a certeza de que combati o bom combate. Consciente do significado da docência, a partir de sua etimologia, jamais fui omisso no cumprimento do dever de apontar caminhos, de conceder apoio aos que se iniciam e prosseguem em sua caminhada pelo mundo jurídico ou que ousam o acesso a novos patamares, jamais fugi à responsabilidade de expressar minha opinião sincera e franca, mesmo assumindo riscos, sobre o justo e o injusto. Nunca, entretanto, tive a pretensão de impor minhas verdades e sempre respeitei, muitas vezes encorajando mesmo, as divergências honestas e bem comigo sobre Direito e Justiça. Fui Professor, integrante do quadro de docentes destas nobres e queridas Arcadas, por quase quarenta anos. Tendo sempre em mente a bela proclamação de Jhering, segundo a qual "a paz é o objetivo do Direito e a luta é o meio de atingi-la", Professor continuo e continuarei 
sendo, procurando dar minha contribuição para que sobre todos os valores prevaleça a dignidade da pessoa humana e para que a eliminação das injustiças leve à conquista da paz. 